\title{
EDUCAÇÃO E IDEOLOGIA TECNOCRÁTICA NA DITADURA MILITAR
}

\author{
Amarilio Ferreira Jr. * \\ MARISA BitTAR **
}

\begin{abstract}
RESUMO: O objetivo deste artigo é examinar a ideologia tecnocrática subjacente à educação brasileira durante a vigência da ditadura militar (1964-1985). Adotamos a premissa segundo a qual as reformas educacionais implementadas após 1964 ficaram marcadas tanto pelo modelo de modernização autoritária do capitalismo brasileiro adotado a partir de 1964, quanto pela teoria econômica do "capital humano". A propaganda ufanista, que tinha como lema o "Brasil Grande Potência", gerado pela "eficiência técnica" aplicada na forma de administrar o Estado e as suas empresas, também teve os seus corolários ideológicos no âmbito da própria política educacional levada à prática após a reforma universitária de 1968 e a reforma da educação de $1^{\circ}$ e $2^{\circ}$ graus de 1971 . Assim, o sistema nacional de educação que emergiu com as reformas da ditadura militar foi marcado pela ideologia tecnocrática, que propugnava uma concepção pedagógica autoritária e produtivista na relação entre educação e mundo do trabalho.
\end{abstract}

Palavras-chave: História da educação. Educação tecnocrática. Ditadura militar.

\section{TeChNiCAL EDUCATION AND IDEOLOGY IN THE DICTATORSHIP}

ABSTRACT: This article studies the technical ideology underlying the Brazilian education during the military dictatorship (19641985). We assume that the educational reforms implemented after

* Doutor em História Social e professor associado do Departamento de Educação da Universidade Federal de São Carlos (UfSCAR). E-mail: ferreira@ufscar.br

** Doutora em História Social, professora titular de História da Educação e Coordenadora do Programa de Pós-Graduação em Educação da UFSCAR. E-mail: bittar@ufscar.br

Cad. Cedes, Campinas, vol. 28, n. 76, p. 333-355, set./dez. 2008

Disponível em <http://www.cedes.unicamp.br> 
1964 were marked both by the Brazilian capitalist model of authoritarian modernization and by the economic theory of "human capital". Generated by the "technical efficiency" applied to the management of State and its organizations, the conceit whose theme was "Brazil as a Great Power" also had consequences on the educational polices implemented after the 1968 and 1971 university reforms. Thus, the national educational system created by the dictatorship reforms was marked by the technocrat ideology that defended an authoritarian, productivist pedagogic conception of the relation between education and the world of work.

Key words: History of education. Technical education. Dictatorship.

\section{Introdução}

$\mathcal{A}$ data de 31 de março de 1964 representa a mudança institucional mais grave da história do Brasil na segunda metade do século XX. Mas qual foi o seu significado? A aliança empresarial-militar, que golpeou a ordem institucional implantada após 1946, não propugnava alterar a essência do processo de desenvolvimento do capitalismo brasileiro que se iniciara em 1930. Para os golpistas, o Estado nacional continuaria a ser o demiurgo de uma sociedade urbano-industrial moderna. Mas, as elites econômicas, políticas e militares, que depuseram o presidente João Goulart (1961-1964), não aceitavam os pressupostos ideológicos da política nacional-populista, levada a cabo pelo Estado brasileiro desde a chamada "Era Vargas" (1930-1945).

A questão que se colocava para os golpistas era a seguinte: as classes subalternas, capitaneadas pela classe operária fabril, significavam uma ameaça para o processo contraditório e complexo do desenvolvimento e modernização do capitalismo brasileiro. No contexto internacional da Guerra Fria (1947-1991), as reivindicações dos trabalhadores representavam, para as elites, uma luta que almejava a sociedade socialista. Era necessário, portanto, interromper o processo histórico que havia se inaugurado após 1930 e, por conseguinte, libertar o Estado demiurgo da pressão dos "de baixo".

As suas várias tentativas de chegar ao poder pela via democrática haviam falhado, mesmo com a vitória eleitoral de Jânio Quadros em 1960. Assim, o que restou para as elites reacionárias e conservadoras 
foi o expediente do golpe de Estado. Contudo, o regime político que se implantou depois de 1964 não pôs fim ao processo de intervenção do Estado na economia. Muito pelo contrário, acelerou ainda mais a modernização do capitalismo e, por extensão, consolidou a sociedade urbano-industrial brasileira depois do chamado "milagre econômico" (1969-1974). As altas taxas de crescimento do PIB, que atingiam uma média próxima de $10 \%$ ao ano (Simonsen, 1979), somente foram possíveis em função da exclusão das classes trabalhadoras das tomadas de decisão política nacional. Para tanto, o regime militar desencadeou um processo de supressão das liberdades democráticas desde os primeiros atos instituídos, a partir de abril de 1964.

Os governos militares adotaram um movimento político de duplo sentido: ao mesmo tempo em que suprimiam as liberdades democráticas e instituíam instrumentos jurídicos de caráter autoritário e repressivo, levavam à prática os mecanismos de modernização do Estado nacional, no sentido de acelerar o processo de modernização do capitalismo brasileiro. Em síntese: propugnavam a criação de uma sociedade urbano-industrial na periferia do sistema capitalista mundial, pautada pela racionalidade técnica. No lugar dos políticos, os tecnocratas; ${ }^{1}$ no proscênio da política nacional, as eleições controladas e fraudadas; no âmbito do mundo do trabalho, ${ }^{2}$ a prevalência do arrocho salarial; na lógica do crescimento econômico, a ausência de distribuição da renda nacional; na demanda oposicionista pela volta do Estado de direito democrático, a atuação sistemática dos órgãos de repressão mantidos pelas Forças Armadas: eis como a ditadura militar executou o seu modelo econômico de aceleração modernizadora e autoritária do capitalismo no Brasil. Foi assim que o Estado, com grande poder de ordenação da sociedade civil, assumiu uma face ideológica fundada no princípio da racionalidade técnica como o único mecanismo político válido para a consolidação da revolução burguesa que havia se iniciado depois de 1930.

$\mathrm{Na}$ esteira desse processo, o regime militar implementou as reformas educacionais de 1968, a Lei n. 5.540, que reformou a universidade, e a de 1971, a Lei n. 5.692, que estabeleceu o sistema nacional de $1^{\circ}$ e $2^{\circ}$ graus, pois ambas tinham com escopo estabelecer uma ligação orgânica entre o aumento da eficiência produtiva do trabalho e a modernização autoritária das relações capitalistas de produção. Ou seja, 
a educação no âmbito do regime militar foi concebida como um instrumento a serviço da racionalidade tecnocrática, com o objetivo de se viabilizar o slogan "Brasil Grande Potência".

Portanto, partimos do pressuposto de que é impossível a compreensão do sentido mais geral das reformas educacionais postas em prática durante a ditadura militar, sem antes analisarmos, mesmo que minimamente, o significado estrutural do modelo econômico concebido pela tecnocracia que se colocara a serviço dos governos dos generais-presidentes. Por conseqüência, defendemos a tese de que a política educacional do período entre 1964 e 1985 estava, em última instância, vinculada organicamente ao modelo econômico que acelerou, de forma autoritária, o processo de modernização do capitalismo brasileiro. Ainda mais: foram reformas educacionais que estavam inseridas num contexto histórico de transição de uma sociedade agrária para uma sociedade urbano-industrial, cujas transformaçôes societárias se desenrolavam desde 1930.

Além disso, para empreendermos a nossa pesquisa, optamos pelo uso de fontes capazes de evidenciar o pensamento tecnocrático tal como ele foi formulado pelos intelectuais do regime, ou seja, utilizamos aqui, preferencialmente, os próprios formuladores da concepção tecnocrática, com o propósito de fazer-lhes o contraponto e, por conseguinte, revelar o seu caráter educacional elitista e autoritário.

\section{O modelo econômico da ditadura militar}

Os traços mais expressivos da macroeconomia adotada pelo modelo de modernização das relações capitalistas, durante a ditadura militar (1964-1985), não foram alterados, apesar das mudanças que ocorreram na economia mundial depois de 1974. Assim, o modelo econômico implementado foi estruturado com base nos seguintes princípios: política de arrocho salarial das classes trabalhadoras; ${ }^{3}$ indexação dos preços das mercadorias de acordo com a correção monetária determinada pelos índices de inflação; política cambial que privilegiava a sobrevalorização do dólar; fim da estabilidade no emprego, por meio da adoção do Fundo de Garantia do Tempo de Serviço (FGTS); modernização e ampliação da infra-estrutura ligada aos setores agrícola e industrial; política de juros subsidiados, com taxas 
abaixo dos índices inflacionários, para os vários ramos produtivos; direcionamento da produção agrário-industrial para o mercado externo, em detrimento do mercado interno (Netto, 1972; Simonsen, 1979; Campos, 1979).

O coronel Jarbas Passarinho, ministro da Educação do governo do general-presidente Emílio Garrastazu Médici, ${ }^{4}$ por exemplo, reputa ao governo do general-presidente Humberto Castelo Branco os fundamentos do modelo econômico adotado durante a ditadura militar. ${ }^{5}$ Quando se trata de fazer comparações entre as heranças deixadas pelos militares, ele assevera que, "de um lado, temos orgulho do resultado econômico e não tanto do resultado político" (Passarinho, 2003, p. A2). O balanço, portanto, seria favorável à política econômica. Cabenos indagar, porém, quais foram os elementos utilizados pelo general para implementar o tão decantado modelo econômico? O coronel, por seu lado, exige uma postura de neutralidade ideológica de todos aqueles que buscam responder tal questão. Para ele, quem efetivamente

(...) analisar com isenção o governo Castelo Branco verá que foi o responsável por uma revolução, por mudanças radicais e em curto tempo. Modernizou o Estado. As reformas de base, pedra angular retórica do deposto governo, se iniciaram no seu governo. A política salarial defendeu o trabalhador do efeito perverso da inflação, domada em dois anos. O Banco Central, o Banco Nacional de Habitação, a reforma do ensino superior e a reforma fiscal foram implantadas no breve governo. O Estatuto da Terra condenava os latifúndios à extinção por imposto progressivo. As 14 legendas partidárias existentes, comprometedoras da democracia representativa, foram reduzidas a duas, pelo bipartidarismo que veio a ser extinto em 79. Pela primeira vez os trabalhadores rurais, até então politicamente explorados, mas não apoiados, tiveram direito à aposentadoria, pelo Fundo Rural, lei de Castelo implantada no governo Costa e Silva. (Passarinho, 1999, p. A2)

Assim, os feitos econômicos só se realizaram graças ao sacrifício da política. O bloco empresarial-militar, que tomou de assalto o Estado em 1964, considerava a pluralidade das tendências político-partidárias como um fator "comprometedor da democracia representativa", ou seja, para os golpistas, era fundamental excluir da vida política brasileira a influência exercida pelo nacional-populismo. Daí a redução do espectro partidário a apenas duas agremiações: ARENA e MDB. Desse modo, a simplificação da política pelo viés do autoritarismo funcionou 
como indutor do crescimento das forças produtivas que elevaram o Brasil do "490 lugar" para a posição de "80 lugar" no âmbito da economia mundial (Passarinho, 2002, p. A2). Contudo, durante o ciclo militar, este foi um dos segredos de polichinelo mais bem guardados pela burocracia empresarial. $\mathrm{Na}$ visão hegemônica da época, a melhor maneira de se governar a economia não era pelos pressupostos das liberdades democráticas, mas, sim, por meio de um regime político de caráter tecnocrático.

O modelo econômico executado pela ditadura militar era regido por "um movimento pendular". Segundo Ianni (1979, p. 288-289), "em um dos seus pólos estaria o projeto de criar um capitalismo nacional, ao passo que no outro estaria o projeto de desenvolver um sistema capitalista associado (...), sob a égide dos Estados Unidos". A coabitação dessas duas lógicas econômicas atravessou todo o período do regime militar. $\mathrm{O}$ pêndulo econômico inclinava ora para o nacionalismo, ora para a internacionalização subordinada. Eugenio Gudin foi o grande defensor da tese sobre a plena associação da economia brasileira à norte-americana. $\mathrm{O}$ exemplo mais notório foi a polêmica nacional que travou, no pré-64, contra a Lei de Remessas de Lucro. No início de1962, depois que o projeto havia passado pela primeira votação na Câmara dos Deputados, ${ }^{6}$ Gudin (1965, p. 344) replicou que a "legislação sobre as remessas de lucro" aprovada era uma das "providências mais prejudiciais para o desenvolvimento econômico do País".

Após 1964, cessou a discussão sobre a internacionalização ou não da economia brasileira. Não era mais necessária. A tendência ideológica favorável à tese da associação orgânica com o chamado "mundo livre" tinha se imposto pelo argumento da força. Liquidada a posição nacional-populista, pela via da repressão estatal, a ditadura militar se viu liberada para impor os elementos econômicos que permitiriam a tão almejada forma de vinculação internacional. Os fundamentos da nova política ficaram consubstanciados no Programa de Ação Econômica do Governo (PAEG), adotado na administração do general-presidente Humberto Castelo Branco. O plano econômico saiu da lavra do ministro Roberto $\mathrm{Campos}^{7}$ (Planejamento), mas foi executado pelo ministro Octávio Gouveia de Bulhões (Fazenda). Décadas depois, Campos registrou, em suas memórias, as semelhanças e diferenças que existiram entre o plano econômico adotado no início do regime militar e 
o modelo de modernização capitalista levado a cabo pelos países denominados "tigres asiáticos". O mentor intelectual do PAEG assim se expressou:

O receituário das reformas brasileiras em meados da década dos 60 era surpreendentemente semelhante ao modelo dos tigres asiáticos. Havia observância das duas regras de ouro: juros reais positivos e taxa cambial realista. A política monetária e fiscal era ortodoxa, em ambos os casos. Admitia-se um importante papel para o Estado na fixação da estratégia do crescimento e na criação de condiçôes para a modernização capitalista. Entretanto, a distribuição de renda era bastante melhor nos tigres asiáticos. Geralmente, isso se atribui a quatro fatores: (1) a reforma agrária do pós-guerra, que diminuiu a pobreza rural e atenuou a concentração do poder político nas zonas urbanas; (2) o maciço esforço de educação, derivado em parte da tradição confuciana e em parte do esforço governamental deliberado de educação básica, sem o beletrismo latino; (3) a priorização das indústrias intensivas de mão-de-obra, orientadas para exportação; (4) a implantação (exceto em Taiwan) de programas de planejamento familiar. Alguns desses elementos, mas não todos, figuravam nas propostas do governo Castello Branco [sic]. (Campos, 1994, p. 633-634)

Independentemente das comparações realizadas a posteriori, o que a dupla de ministros efetivamente tinha como escopo, na década de 1960, era "acelerar o ritmo de desenvolvimento econômico do País, interrompido no biênio 1962-1963" (Ianni, 1979, p. 231), mesmo que para isso fosse necessário sacrificar a "distribuiçāo de renda" e promover, por conseguinte, ainda mais concentração do fausto exibido pelas elites desde o longo período escravocrata. Mas os primeiros resultados do PAEG só começaram a frutificar durante o governo do general-presidente Arthur da Costa e Silva (15/03/1967 a 31/08/1969). A retomada do "desenvolvimento" (Passarinho, 2001, p. A2) econômico, a partir dos chamados "anos de chumbo", foi classificada por Passarinho (2003, p. A2) da seguinte forma:

O milagre econômico (termo que eu ouvi do presidente da Alemanha Ocidental, em discurso no Itamaraty, em 1981) resultou da semeadura feita pelo presidente Castelo Branco e dos frutos colhidos particularmente nos governos Costa e Silva e Emílio Médici, quando o PIB cresceu acima de $10 \%$ ao ano. Nem um só petrodólar entrou no Orçamento até então. No governo Geisel, quando o preço do barril do petróleo passou de US\$ 2 para 14, foi que o presidente decidiu tomar empréstimos para 
vencer a crise, mas com a condição de investir em projetos reprodutivos, o que se deu, com apenas dois malogros: a Ferrovia do Aço e o Acordo Brasil/Alemanha para energia nuclear. Geisel não tinha outra alternativa, a menos que paralisasse o País por falta de suprimento de petróleo de que éramos dependentes, como o maior importador de Terceiro Mundo, escravos do diesel, querosene, gasolina, para a indústria, os transportes de terra, mar e ar e o consumo doméstico.

O aludido "milagre econômico" só foi possível, segundo Furtado (1972), porque a ditadura militar adotou uma estratégia de desenvolvimento fundada em três linhas de ação que se complementavam: a) reorientou o processo de concentração da riqueza e da renda; b) reduziu a taxa do salário real básico com respeito à produtividade média do sistema; e c) fomentou, em particular, mediante subsídios, a exportação de produtos industriais, objetivando aliviar os setores produtivos que enfrentavam insuficiência de demanda. Assim, a composição do receituário adotado pelo modelo econômico, tal como já foi afirmado, tinha os seguintes ingredientes: arrocho salarial; concentração de riqueza; financiamento do capital por meio de subsídios, correção monetária como mecanismo de controle inflacionário; adoção "de uma política governamental muito bem sucedida, que visava atrair as grandes empresas transnacionais e fomentar a expansão das subsidiárias destas já instaladas no País" (Furtado, 1974, p. 103). O "liquidificador" que possibilitou historicamente dissolver todos estes ingredientes numa só política econômica foi a brutal repressão policial-militar que se abateu sobre as forças democráticas.

Foi com base nessa configuração de modelo econômico que o regime militar programou as suas reformas educacionais. Dito de outra forma: o projeto "Brasil, país do futuro", assentado no processo de modernização autoritária das relações capitalistas de produção, repercutiu, em decorrência das demandas científicas e tecnológicas que a sociedade urbano-industrial exigia, tanto no âmbito da reforma universitária de 1968 quanto na reforma da educação básica que instituiu o sistema nacional de $1^{\circ}$ e $2^{\circ}$ graus, em 1971. A cronologia dos acontecimentos é reveladora da lógica economicista que presidia os objetivos propugnados pelos governos dos generais-presidentes: primeiramente, os planejamentos econômicos, nos quais estavam estabelecidas as diretrizes que vinculavam organicamente economia e educação, e 
depois a materialização dessas diretivas no âmbito das reformas educacionais. A sucessão dos fatos seguiu a seguinte linha do tempo: Plano de Ação Econômica do Governo (1964-1966), Plano Decenal de Desenvolvimento Econômico e Social (1967-1976), Programa Estratégico de Desenvolvimento (1968-1970), Reforma Universitária (1968) e Lei de Diretrizes e Bases para o Ensino de $1^{\circ}$ e $2^{\circ}$ Graus (1971). Ou seja: no contexto da estratégia de crescimento acelerado e autoritário do capitalismo brasileiro, adotada durante a ditadura militar, a educação seguia a lógica dos interesses econômicos.

\section{Educação e tecnicismo na ditadura militar}

O decano dos economistas liberais brasileiros, Eugênio Gudin (1886-1986), em artigo publicado em 12/03/1971, estabeleceu a diferença entre os intelectuais e os tecnocratas quando se tratava da função de gerenciar as políticas estatais. Para ele, o estabelecimento da distinção era importante porque:

(...) o técnico (...) há de ser um especialista no assunto da pasta que é chamado a dirigir (economista para a Fazenda, engenheiro para Transportes ou para Energia, eletrônico para Telecomunicaçôes etc.), o gênero intelectuais abrange várias espécies. Ninguém negaria por exemplo aos membros da Academia Brasileira de Letras o diploma de intelectuais, mas também ninguém, em seu juízo perfeito, lhes entregaria postos de governo, salvo honrosíssimas exceções. (Gudin, 1978, p. 145)

Anos depois, ele insistiria no mesmo diapasão, ou seja, de que os ditos "técnicos" eram as melhores soluções políticas para a administração das coisas de Estado. Em outro artigo, datado de 7/4/1975, desta feita defendendo a intervenção dos militares na política nacional, argumentava que um dos grandes feitos da "Revolução de 1964" era ter se baseado no "princípio da convocação de técnicos (em vez de políticos) para os ministérios específicos (...). Bem assim vedada a manipulação pelos políticos das verbas orçamentárias e os recursos ao engavetamento indefinido dos projetos do governo" (idem, ibid., p. 166). O mais intelectual dos seus discípulos, Roberto Campos, também era um empedernido defensor da tecnocracia. Em artigo intitulado "Em defesa dos tecnocratas", de 25/7/1967, o ministro do 
Planejamento do governo de Castelo Branco interditava a crítica aos tecnocratas, com o argumento de que eles eram rápidos e eficientes nas tomadas de decisões que o regime militar teve que adotar após 1964. Num determinado excerto, vaticinava:

(...) o problema que se apresentava aos tecnocratas era o seguinte: como modernizar instituiçôes obsoletas, para ajustá-las às necessidades de uma sociedade atingida pela inflação e desejosa de acelerar o desenvolvimento? Como fazê-lo, sem alongar demasiadamente o período de poderes excepcionais? Como redefinir as relações entre o Executivo e o Legislativo, de maneira mais consoante com a velocidade e complexidade das decisões econômicas? (...) É óbvio que, ao se aproveitar de exceção para acelerar o processo de modernização institucional, vários dos diplomas legais se macularam de imperfeições e, em alguns casos, terão que ser revistos com a sedimentação da experiência. Na opção, entretanto, entre o imobilismo perfeicionista e a experimentação modernizante, a atitude dos tecnocratas parece ter sido a mais produtiva (...). Problema mais complexo é o da institucionalização das relações entre o Executivo e o Legislativo, de forma compatível com as exigências da política monetária e de planejamento econômico, ambos os quais requerem velocidade de decisão e um certo grau de centralização de comando. (Campos, 1968, p. 129-130)

Portanto, a defesa dos intelectuais orgânicos da ditadura militar sobre o papel dos tecnocratas no âmbito do Estado brasileiro estava diretamente relacionada à supressão das liberdades democráticas e à célere modernização das relações capitalistas de produção, isto é, sem democracia era impossível criticar, fiscalizar e controlar as decisóes econômicas e sociais adotadas pelos tecnocratas, em relação às políticas implementadas pelos governos que se sucederam entre 1964 e 1985 . A conseqüência daí derivada foi a institucionalização do tecnicismo como ideologia oficial de Estado. Assim, a difusão generalizada dessa ideologia ganhou materialidade, particularmente, após a edição do Ato Institucional n. 5 (AI-5), em dezembro de 1968. A partir de então, a ditadura militar, com base na censura imposta aos meios de comunicação de massa, produziu um conjunto articulado de idéias, valores, opinióes e crenças, segundo o qual a tecnocracia era a melhor forma de se governar a sociedade brasileira.

Desse modo, podemos afirmar que foi depois de 1964, com a implantação da ditadura militar, que a tecnocracia começou a tomar 
vulto no âmbito do Estado brasileiro. Ou seja, o regime militar primou por estabelecer um governo de técnicos, com base no fortalecimento centralizador do Poder Executivo e pautando as ações administrativas pelo primado do econômico sobre os aspectos políticos e sociais. Neste contexto, a ideologia tecnicista serviu como um invólucro mistificador do projeto "Brasil Grande Potência" que os governos dos generais-presidentes utilizaram para justificar a supressão das liberdades democráticas e, por conseguinte, a repressão política que se abateu contra as tendências oposicionistas. Assim, a propensão em transformar o Estado aos moldes de uma grande empresa, gerenciada por técnicos que absorvessem as funções da política pela dita eficiência que eles representavam, constituiu-se no leitmotiv da ideologia tecnicista que embalou o regime militar.

No tocante à questão educacional, os tecnocratas defendiam como pressuposto básico a aplicação da "teoria do capital humano", como fundamentação teórico-metodológica instrumental para o aumento da produtividade econômica da sociedade. A tecnocracia brasileira era filiada aos ditames emanados da "escola econômica" sediada na Universidade de Chicago (EUA) e, portanto, afeita às teorias aplicadas à educação desenvolvidas por Theodore W. Schultz (1902-1998). Para ele, a "instrução e a educação" eram, antes de tudo, valores sociais de caráter econômico. Portanto, a "instrução/educação" é considerada como um "bem de consumo", cuja principal propriedade é ser "um bem permanente de longa duração", por conseguinte, diferente de outras mercadorias consumidas pelos indivíduos durante as suas vidas (Schultz, 1973, p. 24-25). O professor de economia da Universidade de Chicago propugnava ainda que:

Os investimentos na instrução não podem ser minimizados; muito ao contrário, são de tal magnitude que alteram, radicalmente, as estimativas, geralmente aceitas, do total das poupanças e da formação de capitais, que estão em curso. Deverão ser reformulados os conceitos estabelecidos com relação aos elementos de formação do pagamento e salários (renda relativa), à distribuição da renda por pessoa e às fontes de crescimento econômico. (Idem, ibid., p. 26)

Assim, a "teoria do capital humano" desenvolvida por Schultz estabelecia uma relação direta entre educação e economia, na medida em 
que atribuía a primeira a capacidade de incrementar a produtividade da segunda. Portanto, a educação deveria ser condicionada pela lógica que determinava o crescimento econômico da sociedade capitalista. Mais tarde, na obra $O$ capital humano, publicada no início da década de 1970, Schultz (op. cit., p. 35) avança nas suas teorias sobre a relação entre educação e economia, defendendo a tese de que "os trabalhadores transformaram-se em capitalistas, não pela difusão da propriedade das ações da empresa, como o folclore colocaria a questão, mas pela aquisição de conhecimentos e de capacidades que possuem valor econômico". Assim, para a "Escola de Chicago", a educação não só alavancava a produtividade econômica como também transfigurava o trabalhador em capitalista, com base na quantidade e qualidade de novos conhecimentos que ele agregava à sua própria força de trabalho, ou seja, num capitalista proprietário de bens simbólicos metamorfoseados em "capital humano".

Durante a ditadura militar, as relações que se estabeleceram entre planejamento econômico, modernização acelerada das relações capitalistas de produção, tecnocracia e educação tinham na "teoria do capital humano" o seu elemento vital, a seiva ideológica que alimentava o projeto societário materializado no slogan "Brasil Grande Potência". O economista Mario Henrique Simonsen (1935-1997), ${ }^{8}$ em 1969, fazia um diagnóstico do sentido que a educação brasileira havia assumido, historicamente, com base na seguinte interpretação:

Um dos maiores defeitos da chamada tradição cultural brasileira é o de quase sempre ter encarado a educação como um bem de consumo, muitas vezes até supérfluo, e não como matéria-prima básica de produção. A cultura, nesse sentido tradicional, constituía um complemento refinado ao lazer, e não um instrumento de trabalho. (Simonsen, 1969, p. 222)

Para superar os traços considerados negativos da "tradição cultural brasileira", que afetavam a educação e a colocavam como caudatária de estruturas curriculares de caráter humanístico e pouca afeita à formação técnica e científica e, portanto, desconectada objetivamente dos requisitos impostos pelo mercado de trabalho, Simonsen recomendava um receituário educacional composto de várias medidas, entre as quais destacamos as que se seguem: 


\section{POLÍTICA EDUCACIONAL DEFENDIDA POR MÁRIO HENRIQUE SIMONSEN}

\begin{tabular}{|c|c|c|}
\hline Educação primária & Educação média & Educação superior \\
\hline $\begin{array}{l}\text { Cumprimento da } \\
\text { obrigatoriedade escolar na } \\
\text { faixa etária de } 7 \text { a } 14 \text { anos, } \\
\text { nas capitais e nos grandes } \\
\text { centros urbanos } \\
\text { (“Operaçáo Escola”). }\end{array}$ & $\begin{array}{l}\text { A reformulação do ensino ginasial, } \\
\text { de modo que ele venha a constituir, } \\
\text { com o nível primário, um sistema } \\
\text { fundamental contínuo, capaz de } \\
\text { atender à elevação dos padrōes } \\
\text { qualitativos, assegurando a formação } \\
\text { básica de educando para atuar nas } \\
\text { atividades da indústria, agricultura e } \\
\text { serviços, após treinamento intensivo } \\
\text { e rápido para o trabalho. }\end{array}$ & $\begin{array}{l}\text { Ampliação das matrículas, } \\
\text { especialmente nas modalidades } \\
\text { profissionais consideradas } \\
\text { prioritárias pelo seu caráter social } \\
\text { e interesse no processo de } \\
\text { desenvolvimento econômico } \\
\text { nacional (“Operação- } \\
\text { Produtividade”). }\end{array}$ \\
\hline $\begin{array}{l}\text { Assistência ao educando } \\
\text { (alimentação, serviços de } \\
\text { saúde, material escolar } \\
\text { etc.). }\end{array}$ & $\begin{array}{l}\text { Elevação do nível do pessoal docente, } \\
\text { técnico e administrativo, } \\
\text { notadamente nas áreas do ensino } \\
\text { mais relacionado com o } \\
\text { desenvolvimento. }\end{array}$ & $\begin{array}{l}\text { Intensificação da pós-graduação, } \\
\text { em nível de mestrado e doutorado, } \\
\text { a fim de formar pessoal docente } \\
\text { qualificado e proporcionar recursos } \\
\text { humanos de alto nível para o } \\
\text { desenvolvimento. }\end{array}$ \\
\hline $\begin{array}{l}\text { Aperfeiçoamento do } \\
\text { magistério. }\end{array}$ & $\begin{array}{l}\text { Formação e treinamento de } \\
\text { professores de ciências, disciplinas } \\
\text { específicas de ensino técnico e } \\
\text { práticas educativas. }\end{array}$ & $\begin{array}{l}\text { Assistência ao estudante, de forma } \\
\text { coordenada e em função de sua } \\
\text { situação econômica e } \\
\text { aproveitamento escolar. }\end{array}$ \\
\hline $\begin{array}{l}\text { Mudança do sistema de } \\
\text { promoção (Avaliação). }\end{array}$ & $\begin{array}{l}\text { Expansão dos programas de } \\
\text { equipamento escolar, especialmente } \\
\text { de salas-ambiente, oficinas para os } \\
\text { ginásios orientados para o trabalho e } \\
\text { para os colégios industriais. }\end{array}$ & $\begin{array}{l}\text { Modificação do sistema de } \\
\text { financiamento, com gradual } \\
\text { eliminação da gratuidade } \\
\text { generalizada e modificação do } \\
\text { regime de subvenções às unidades } \\
\text { de ensino privado. }\end{array}$ \\
\hline $\begin{array}{l}\text { Utilização de recursos } \\
\text { audiovisuais no ensino. }\end{array}$ & $\begin{array}{l}\text { Aperfeiçoamento profissional do } \\
\text { pessoal técnico de nível médio } \\
\text { colegial. }\end{array}$ & \\
\hline \multicolumn{3}{|l|}{$\begin{array}{l}\text { Expansão criteriosa da rede } \\
\text { de escolas públicas. }\end{array}$} \\
\hline $\begin{array}{l}\text { Erradicação do } \\
\text { analfabetismo nas capitais, } \\
\text { na faixa etária de } 15 \text { a } 30 \\
\text { anos. }\end{array}$ & & \\
\hline
\end{tabular}

Fonte: Simonsen (1969, p. 238-241).

Portanto, para a alta tecnocracia brasileira da ditadura militar, a tarefa que estava posta era a criação dos fundamentos de um sistema nacional de ensino, com base nos aparelhos estatais, que desse curso ao 
estabelecimento da organicidade entre educação e o aumento produtivo da economia nacional. Era necessário apetrechar o Estado nacional da capacidade de planejar a educação de acordo com os interesses socioeconômicos do mercado capitalista. Para tanto, impunha-se a universalização da escola primária e média e, particularmente, a ênfase na questão curricular referente ao ensino de matemática e ciências naturais. Quanto ao ensino superior, previa-se a ampliação das vagas no âmbito dos cursos de graduação voltados para as profissões tecnológicas. Além disso, privilegia-se a estruturação dos programas de pósgraduação com a dupla função de produzir conhecimentos exigidos pela demanda do crescimento acelerado da produção econômica e, ao mesmo tempo, de formar novos quadros capacitados para a geração de ciência e tecnologia.

Já no âmbito da baixa tecnocracia, urgia a formação de mão-deobra para aumentar a produtividade do PIB brasileiro; não era possível esperar a estruturação de um sistema nacional de ensino obrigatório e universal. Para o Estado tecnocrático, era preciso incorporar a massa da juventude que se constituía na prole das classes populares - ou, como se expressava o ex-presidente do Banco Nacional de Desenvolvimento Econômico, engenheiro Glycon de Paiva (1972, p. 34), a prole do "gado humano" (notadamente nordestina) - ao esforço de construção do "Brasil Grande Potência". Para os amplos contingentes de jovens brasileiros que viviam na pobreza ou na miséria, os tecnocratas eram explícitos quanto ao receituário a ser adotado: propugnavam a "formação paramilitar de trabalho de menores". Ou seja, para resolver o problema da "oportunidade empregatícia de menores, economicamente marginalizados, sobretudo dos localizados no empobrecido Nordeste, todavia, também dos residentes nos demais núcleos de miséria, rural e urbana" (Fischlowitz, 1971. p. 167), a tecnocracia defendia a necessidade de se incorporar o "trabalho de menores" ao processo de modernização acelerada da sociedade capitalista brasileira. Tal política de formação paramilitar do trabalho de crianças e jovens teria o seguinte desdobramento:

a) a categoria etária, a ser prioritariamente amparada, seria integrada por menores de 14 a 18 anos, (...) abranger somente rapazes, com a exclusão de moças; 
b) voluntariamente recrutados (...) dentro de mocidade desocupada, rural e urbana, sem quaisquer barreiras discriminatórias, ligadas à cor, origem social, credos religiosos etc., deveriam passar pelo crivo de sua pré-seleção, em obediência a critérios higiênicos e intelectuais, estes, porém, interpretados de modo maleável, devendo (...) ficar eliminados os que apresentarem antecedentes delituosos;

c) uma vez admitidos ao serviço, teriam que assumir firmes compromissos no sentido de observarem rigorosamente as diretrizes disciplinares e de ficarem, num determinado prazo mínimo, à sua disponibilidade;

d) as Companhias e Pelotôes de Trabalho, assim formados, seriam subordinados aos Comandos Regionais de Exércitos, os quais, todavia, se articulariam com os competentes órgãos de Administração Civil, devendo contar com Instrutores, Monitores e Assistentes Sociais, além de pessoal médico e paramédico, colocados à sua disposição por estes órgãos ou por entidades incluídas na sua área jurisdicional (tais, como sejam, p. ex., INPS, SESI, SESC, SENAI E SENAC, FUNABEM, LBA etc.);

e) os incluídos nessas formações não teriam qualidade nem de trabalhadores assalariados, nem de pracinhas que prestem serviço militar, fazendo jus - fora de alimentação, alojamento e vestuário (uniformes de trabalho), assim como de serviço médico e de seguro de acidentes pessoais - apenas à diária, de valor modesto, sem direito a remuneração normal pelo trabalho;

f) muita atenção deveria ser emprestada ao desenvolvimento do espírito idealístico de corpo (própria bandeira, juramento à mesma, concessão de distinções honoríficas etc.). (Fischlowitz, 1971, p. 167)

As fórmulas propostas pelos tecnocratas não mediam as conseqüências quando se tratava de potencializar o processo de modernização autoritária das relações capitalistas de produção. A concepção de paramilitarizar o trabalho da juventude pobre e miserável, durante a ditadura militar, se assemelhava aos programas postos em prática pelos 
regimes fascistas na Europa do período entre guerras (1918-1945). Para os jovens excluídos, em vez da escola e proteção do Estado por meio de políticas sociais baseadas na transferência de renda, a tecnoburocracia preceituava o mercado de trabalho fundado na desumana exploração da "mão-de-obra de menores", pois nem mesmo tinham direito aos salários. Aliás, sobre a prática sistemática do trabalho de crianças e jovens na sociedade brasileira, José de Souza Martins (2006, p. J4) escreveu recentemente que: "o Brasil é um país em que milhões de crianças já nascem quase perto de se tornarem idosas. Muitas delas já estarão cansadas de trabalhar aos 25 anos de idade, porque começaram cedo demais". Contudo, os tecnocratas não pensavam assim.

Apesar dessa adoção do trabalho infantil, como um dos aspectos da política econômica, o ministro da Educação do governo do general Ernesto Geisel (1974-1979), Ney Braga, não chegou a ponto de defender uma concepção de educação que assumisse abertamente um tratamento diferenciado entre crianças e jovens excluídos, de um lado, e crianças e jovens das classes médias e das elites econômicas e políticas, do outro. Ou seja, para os primeiros, se possível, a escolaridade das primeiras letras seguida do inexorável mundo do trabalho. Já para os segundos, a proteção das famílias e o mundo do conhecimento pela via da escolaridade formal. Portanto, longe de advogar a violação dos cânones educacionais defendidos pela tecnoburocracia desde 1964, Ney Braga formulava, em 1975, uma questão educacional cuja solução já possuía uma resposta óbvia para a ideologia tecnicista:

O grande desafio que a política para o desenvolvimento econômico e social do País nos impõe é este: que tipo de educação construir e oferecer às crianças e jovens do Brasil de hoje? A resposta a este desafio está intimamente associada aos objetivos ou fins que aquela política de desenvolvimento pretende alcançar. Tais propósitos estão definidos no II Plano Nacional de Desenvolvimento (II PND). Este autodefine-se como dotado de "forte conteúdo social". Identifica como "objetivo maior de todo o planejamento nacional (...) o homem brasileiro, nas suas diferentes dimensões e aspirações". O modelo de desenvolvimento escolhido é, coerentemente, um "modelo brasileiro de sociedade aberta, social, racional (...)”. (Braga, 1975, p. 3)

$\mathrm{Na}$ vereda da ideologia tecnicista, o discurso do ministro da Educação continuava subjugando a política educacional à razão instrumental do valor econômico, ou seja, o cerne da concepção educacional 
implantada pela ditadura militar estava preservado no texto do ministro: a educação continuava sendo um instrumento social importante para alavancar os ditames preceituados pela política de crescimento econômico determinada pelo II PND. E para complementar, o economista Carlos Geraldo Langoni subsidiava com números a tese educacional desposada por Ney Braga. Langoni (1976, p. 30) elucidava, por meio das suas pesquisas, que "um resultado particularmente importante é o de que os aumentos de produtividade da força de trabalho, através da ampliação dos investimentos líquidos em educação, contribuíram com cerca de $15 \%$ do crescimento do produto". Em síntese, eis o que foi a educação brasileira durante a ditadura militar: uma política social instrumentalizada pela ideologia tecnicista, com o objetivo de impulsionar o projeto de "Brasil Grande Potência", lema que correspondia, no âmbito político-ideológico, ao autoritário "Brasil, ame-o ou deixo-o".

\section{Conclusão}

Tal como foi afirmado na Introdução, partimos do pressuposto de que, quando se trata da história da educação, no contexto da ditadura militar (1964-1985), não é possível apreender o seu sentido mais geral sem o tratamento metodológico que vincula o sistema educacional ao modelo de modernização autoritária que o capitalismo brasileiro sofreu naquele interregno. Portanto, foi com base nessa proposição de pesquisa que procuramos estabelecer o fio condutor entre as características adotadas pelo modelo econômico implantado depois 1964 e a concepção ideológica que permeou as reformas educacionais levadas a cabo pelos governos militares, ou seja, o modelo econômico adotado por eles era considerado como fato histórico antecedente e necessário para a materialização da concepção de educação executada pela tecnocracia, que se apossou dos aparelhos de Estado depois da deposição do presidente João Goulart.

Para justificar o processo político autoritário que subordinou a educação à lógica econômica de modernização acelerada da sociedade brasileira, a tecnoburocracia lançou mão da "teoria do capital humano", ou seja, impôs o discurso unilateral de que o único papel a ser desempenhado pela educação era o de maximizar a produtividade do 
PIB, independentemente da distribuição da renda nacional. Assim, na mesma proporção em que os golpistas de 1964 iam suprimindo as liberdades políticas, os tecnocratas propagavam a ideologia tecnicista como um sistema de idéias dogmaticamente organizado, que servia para legitimar a unidade orgânica entre economia e educação durante o regime militar. Entretanto, a política do regime militar, plasmada pela ideologia tecnicista, redundou também em fracassos. Pois, a "educação pretendida como mecanismo de mudanças profundas, de formação de mão-de-obra capaz e integrada no sistema produtivo" não fez desaparecer, "na realidade, a persistência de altos índices de analfabetismo, mantendo grande parte da população exclusa do acesso a esse mínimo de cultura, ao 'inchaço' da oferta educacional, de profissionais marginalizados, desempregados" (Covre, 1983, p. 219)

A constatação de Covre sobre os resultados negativos obtidos pela política educacional da ditadura militar não era desprovida de referências empíricas. Em 1972, quando das comemorações patrióticas do sesquicentenário da Independência do Brasil, o Instituto de Engenharia de São Paulo, presidido por Flávio de Sá Bierrenbach, publicou um livro intitulado Brasil Potência, cujo conteúdo se referia às conferências realizadas sobre a temática "Problemas econômicos nacionais" e no qual encontramos o seguinte excerto:

Deveríamos limitar o número de matérias ensinadas, ensinar poucas matérias, mas ensinar bem. No primário deveríamos ensinar apenas: Português, Matemática e trabalhos manuais. História, Geografia e Ciências podem ser objeto de leitura e a sala de aula com mapas, desenhos e fotografias ajudariam a dar as primeiras noções dessas matérias. Achamos que, desde o primário até o fim do colégio, deveríamos ensinar poucas matérias. Hoje, um aluno aprende História no Primário, no Ginasial e no Colegial e, quando chega ao Vestibular, não sabe quem descobriu o Brasil. Vamos ensinar uma só vez, mas bem. (Rodrigues, 1972, p. 69; destaques do autor)

O autor desse receituário tecnocrático para a educação, o engenheiro Eduardo Celestino Rodrigues, ex-professor da Escola Politécnica da USP e ex-presidente do Instituto de Engenharia, acabava por corroborar a tese defendida por Covre de que, com a política da ditadura militar, "grande parte da população ficava exclusa do acesso a esse mínimo de cultura" oferecido pelo ensino básico, pois a escola pública que emergiu da reforma educacional consubstanciada na Lei n. 5.962/71 
rapidamente ganhou a fama de nem "ensinar pouco" e, muito menos, "ensinar bem", isto é, era uma escola que negava o conhecimento para os filhos das classes populares, tal como havia proposto o engenheiro Rodrigues. Na conclusão da referida conferência, denominada "Nova tecnologia de ensino", ele fazia a seguinte asserção: "vamos valorizar o homem brasileiro, dando-lhe EDUCAÇÃO, adequada com o nosso tempo e o nosso meio" (idem, ibid., p. 86). Possivelmente, o conceito de "homem brasileiro", prescrito pelo professor da UsP, incluía aqueles "profissionais marginalizados e desempregados” aludidos por Covre.

Para além da ideologia tecnicista que caracterizou a educação, há de se considerar ainda que a herança deixada pela ditadura militar repercute até hoje no sistema educacional brasileiro. Vários elementos que estrangulam, por exemplo, a qualidade de ensino da escola pública são remanescentes das reformas educacionais executadas pelos governos dos generais-presidentes. Destacamos, a título de ilustração, dois aspectos significativos da condição de ser professor do ensino básico, na atual realidade brasileira, que deitam liames profundos na política educacional legada pelo regime militar: o processo aligeirado de formação científico-pedagógico e a política de arrocho salarial a que são submetidos. ${ }^{9}$ A combinação desses dois elementos constitutivos da vida cotidiana dos professores brasileiros representa, até hoje, um nó górdio que estrangula a qualidade de ensino da escola pública brasileira. E esse nó tem uma origem: a política educacional herdada da ditadura militar.

\section{Recebido em novembro de 2007 e aprovado em julho de 2008.}

\section{Notas}

1. Os tecnocratas são os experts (técnicos) responsáveis pela aplicação das novas tecnologias na administração do poder de Estado, ou seja, das técnicas empregadas no âmbito das açōes governamentais com o objetivo de se alcançar a eficiência na racionalização dos recursos financeiros aplicados nos vários setores das políticas estatais. "O governo dos tecnocratas" é denominado pela ciência política de "tecnocracia". A expressão tecnocracia foi "lançada nos Estados Unidos quando da Primeira Guerra Mundial (1914-1918) para designar governo dos técnicos, difundindo-se na época do New Deal”. Em síntese: os tecnocratas são os "managers ou técnicos de categoria superior, colocados à frente de grandes empresas ou de departamentos oficiais do Estado" (Sousa et al., 1998, p. 515-516). Já Bresser Pereira (1982, p. 86) afirma que "o conceito de tecnoburocracia decorre do de técnico. Tecnoburocracia é o governo dos técnicos. É o sistema em que o poder está nas 
mãos dos técnicos, sejam eles economistas, engenheiros, administradores públicos e privados ou militares profissionais. Colocada nesses termos, tecnocracia seria um tipo de oligarquia: a oligarquia dos técnicos. Opōes-se, portanto, a outros sistemas políticos, particularmente à democracia".

2. A expressão "mundo do trabalho" será aqui utilizada como equivalente de "relações sociais de produção" e das implicações daí derivadas, do ponto de vista da organização, distribuição e consumo da produção material no âmbito da sociedade capitalista.

3. A política de arrocho salarial que prevaleceu, de modo geral, durante toda a ditadura militar teve a sua primeira formulação no Plano de Açáo Econômica do Governo (PAEG), adotado durante o governo do general Castelo Branco (1964-1967). O economista Celso Luiz Martone (1975, p. 78) explica que "a política salarial do PAEG introduziu uma sistemática de reajustamento salarial que visava eliminar a instabilidade dos salários reais que se vinha verificando nos últimos anos e manter as médias dos dois anos anteriores à data do reajuste. Antes disso, a correção salarial era feita à mesma taxa de elevação do custo de vida entre as datas de dois reajustes, o que criava uma acentuada instabilidade na remuneração real da mão-de-obra, na medida em que a inflação persistia a taxas elevadas, como era o caso".

4. O coronel Jarbas Passarinho foi também governador do Pará (1964-1965), cargo que ocupou após a cassação do mandato de Aurélio do Carmo pelo general-presidente Humberto Castelo Branco (1964-1967), e senador pelo mesmo estado em três mandatos (19671974; 1975-1982; e 1987-1995). Além disso, foi ministro dos seguintes governos: Trabalho e Previdência Social (Arthur da Costa e Silva); Previdência Social (João Batista Figueiredo); e Justiça (Fernando Collor de Mello). Já sobre a defesa política que atualmente o coronel Jarbas Passarinho faz da ditadura militar, consultar Ferreira Jr. e Bittar (2006c).

5. Segundo o economista José Pedro Macarini (2005, p. 3), o modelo econômico adotado pelo regime militar, que culminou no chamado "Milagre Econômico" (1968-1974), foi uma combinação entre o Plano de Ação Econômica do Governo (PAEG) e o Programa Estratégico de Desenvolvimento (PED), posto em prática durante o governo do general-presidente Costa e Silva (1967-1969).

6. A Lei de Remessa de Lucros foi aprovada pelo Congresso Nacional em setembro de 1962, durante o período parlamentarista do governo João Goulart. A Lei n. 4.131, entretanto, só foi regulamentada em janeiro de 1964, já na fase presidencialista do governo Goulart, ou seja, alguns meses antes do golpe de Estado (Bielschowsky, 2000, p. 412).

7. Roberto Campos (1917-2001) foi economista, diplomata e político. No pré-64 ocupou o cargo de embaixador do Brasil em Washington. Após o golpe de Estado de 1964, foi ministro do Planejamento durante o governo do marechal Castelo Branco (1964-1967) e, depois, parlamentar de 1982 a 1998 (com um mandato no Senado e dois na Câmara Federal). Pela sua submissão aos interesses dos trustes americanos, particularmente durante a década de 1960, Roberto Campos ganhou o apelido, em inglês, de "Bob Fields", cognome outorgado pelas esquerdas brasileiras.

8. O economista Mário Henrique Simonsen foi professor da Escola de Pós-Graduação em Economia da Fundação Getúlio Vargas (RJ), presidente do MOBRal durante o governo do general Emílio Garrastazu Médici (1969-1974), ministro da Fazenda no governo do general Ernesto Geisel (1974-1979) e ministro do Planejamento no governo do general João Batista Figueiredo (1979). Simonsen foi o autor da fórmula matemática que estabeleceu a política salarial do PAEG, ou seja, a fórmula que instituiu a política de arrocho salarial das classes trabalhadoras. 
9. Para um entendimento mais sistemático do significado da política de arrocho salarial a que foram submetidos os professores durante a ditadura militar, consultar Ferreira Jr. e Bittar (2006a, 2006b).

\section{Referências}

BIELSCHOWSKY, R. Pensamento econômico brasileiro: o ciclo ideológico do desenvolvimento. 4. ed. Rio de Janeiro: Contraponto, 2000. $480 \mathrm{p}$.

BRAGA, N. O desafio da política educacional na década de 70. Educação, Brasília, DF, v. 4, n. 15, p. 2-13, jan./mar. 1975.

BRESSER PEREIRA, L.C. A sociedade estatal e a tecnoburocracia. 2. ed. São Paulo: Brasiliense, 1982. p. 301.

CAMPOS, R.O. Em defesa dos tecnocratas. In: Campos, R.O. Do outro lado da cerca...: três discursos e algumas elegias. 2. ed. Rio de Janeiro: APEC, 1968. p. 123-131.

CAMPOS, R.O. A experiência brasileira de planejamento. In: Simonsen, M.H.; Campos, R.O. A nova economia brasileira. 3. ed. Rio de Janeiro: José Olympio, 1979. p. 47-78.

CAMPOS, R.O. A lanterna na popa: memórias. Rio de Janeiro: Topbooks, 1994. 1417p.

COVRE. M.L.M. A fala dos homens: análise do pensamento tecnocrático (1964-1981). São Paulo: Brasiliense, 1983. 327p.

FERREIRA JUNIOR, A.; BITTAR, M. Proletarização e sindicalismo de professores na ditadura militar (1964-1985). São Paulo: Pulsar, 2006a. 105p.

FERREIRA JUNIOR, A.; BITTAR, M. A ditadura militar e a proletarização dos professores. Educação \& Sociedade, Campinas, v. 27, n. 97, p. 1159-1179, set./dez. 2006b.

FERREIRA JUNIOR, A.; BITTAR, M. O coronel Jarbas Passarinho e a ditadura militar: o último intelectual orgânico? In: Maritinas FILHO, J.R. (Org.). O golpe de 1964 e o regime militar: novas perspectivas. São Carlos: UfSCAR, 2006c. p. 2001-223. 
FISCHLOWITZ, E. Crise na mocidade nas classes populares e necessidade de reformulação da política social. In: Silva A. Filho, V. A economia brasileira e suas perspectivas. Rio de Janeiro: APEC, 1971. p. $151-176$.

FURTADO, C. Análise do 'modelo' brasileiro. Rio de Janeiro: Civilização Brasileira, 1972. 122p.

FURTADO, C. O mito do desenvolvimento econômico. 3. ed. Rio de Janeiro: Paz \& Terra, 1974. 117p.

GUDIN, E. Capital estrangeiro e interesse nacional. In: GUDIN, E. Análise de problemas brasileiros: 1958-1964. Rio de Janeiro: Agir, 1965. p. 343-345.

GUDIN, E. Intelectuais ou homens de Estado?. In: Gudin, E. Reflexôes e comentários: 1970-1978. Rio de Janeiro: Nova Fronteira, 1978. p. $145-146$.

GUDIN, E. O papel das Forças Armadas. In: Gudin, E. Reflexões e comentários: 1970-1978. Rio de Janeiro: Nova Fronteira, 1978. p. $165-167$.

IANNI, O. Estado e planejamento econômico no Brasil (1930-1970). 3. ed. Rio de Janeiro: Civilização Brasileira, 1979. 316p.

LANGONI, C.G. A economia da transformação. Rio de Janeiro: Biblioteca do Exército, 1976. 213p.

MACARINI, J.P. A política econômica do governo Médici: 19701973. Nova economia, Belo Horizonte, v. 15, n. 3, 2005. Disponível em: <http://www.scielo.br/scielo.php?script=sci_arttext\&pid=S010363512005000300003\&lng=pt\&nrm=iso >. Acesso em: 19 fev. 2007.

MARTINS, J.S. A infância breve na sociedade da indiferença. $O E$ stado de S. Paulo, São Paulo, 3 dez. 2006. Caderno J (Aliás), p. J4.

MARTONE, C.L. Análise do Plano de Ação Econômica do Governo (paeg) (1964-1966). In: Lafer, B.M. (Org.). Planejamento no Brasil. São Paulo: Perspectiva, 1975. p. 69-89.

NETTO, D. O impulso brasileiro à exportação. In: SAntiago, A.A. et al. Brasil potência. São Paulo: Unidas, 1972. p. 423-432. 
PAIVA, G. Capital humano e desenvolvimento. In: Santiago, A.A. et al. Brasil potência. São Paulo: Unidas, 1972. p. 31-41.

PASSARINHO, J. A batalha perdida. O Estado de S. Paulo, São Paulo, 6 abr. 1999. Caderno A, p. 2.

PASSARINHO, J. Crítica e autocrítica. O Estado de S. Paulo, São Paulo, 17 jul. 2001. Caderno A, p. 2.

PASSARINHO, J. A esquerda no poder. O Estado de S. Paulo, São Paulo, 4 jun. 2002. Caderno A, p. 2.

PASSARINHO, J. Nós e os brazilianistas. O Estado de S. Paulo, São Paulo, 14 jan. 2003. Caderno A, p. 2.

PASSARINHO, J. Pode a história ser apagada?. O Estado de S. Paulo, São Paulo, 8 abr. 2003. Caderno A, p. 2.

RODRIGUES, E.C. Nova tecnologia de ensino. In: Santiago, A.A. et al. Brasil potência. São Paulo: Unidas, 1972. p. 65-86.

SCHULTZ, T.W. O valor econômico da educação. Trad. de P. S. Werneck. 2. ed. Rio de Janeiro: Zahar, 1973. p. 101.

SCHULTZ, T.W. O capital humano: investimento em educação e pesquisa. Trad. de Marco Aurélio de Moura Matos. Rio de Janeiro: Zahar, 1973. 250p.

SIMONSEN, M.H. Brasil 2001. Rio de Janeiro: APEC, 1969. 327p.

SIMONSEN, M.H. O modelo brasileiro de desenvolvimento. In: Simonsen, M.H.; Campos, R.O. A nova economia brasileira. 3. ed. Rio de Janeiro: José Olympio, 1979. p. 1-22.

SOUSA, J.P.G. et al. Tecnocracia. In: SousA, J.P.G. Dicionário de politica. São Paulo: T.A. Queiroz, 1998. p. 515-517. 